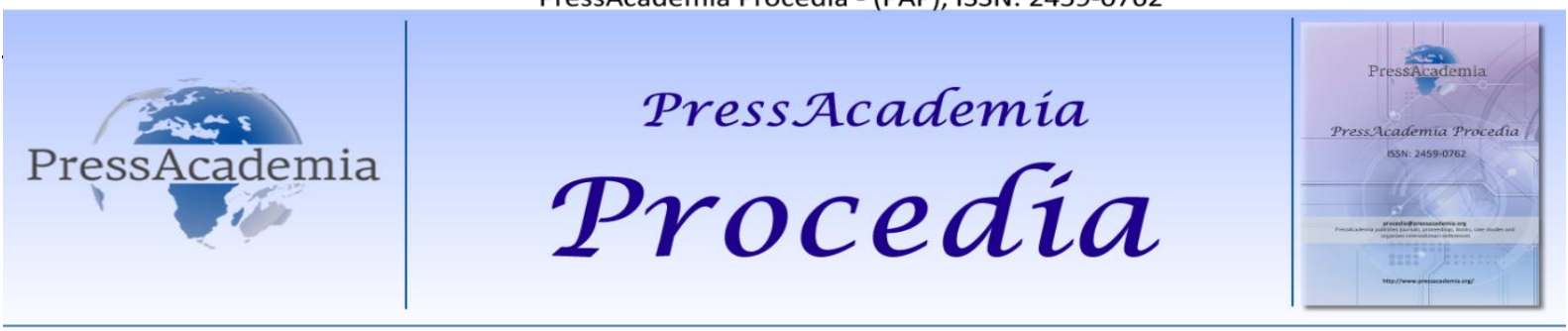

Global Business Research Congress (GBRC), May 24-25, 2017, Istanbul, Turkey.

\title{
IMPORTANCE OF WINNING, SCHADENFREUDE, TEAM IDENTIFICATION AND LOYALTY: EXPLORING RELATIONSHIPS WITH SURVEY DATA FROM TURKEY
}

\author{
DOI: 10.17261/Pressacademia.2017.430 \\ PAP-GBRC-V.3-2017(45)-p.442-446 \\ Caner Ozgen ${ }^{1}$, Metin Argan ${ }^{2}$ \\ ${ }^{1}$ Anadolu University, Eskisehir, Turkey. canerozgen@anadolu.edu.tr \\ ${ }^{2}$ Anadolu University, Eskisehir, Turkey. margan@anadolu.edu.tr
}

\section{To cite this document}

Özgen, C. and M. Argan, (2017). Importance of winning, schadenfreude, team identification and loyalty: exploring relationships with survey data from turkey. PressAcademia Procedia (PAP), V.3, p.442-446.

Permemant link to this document: http://doi.org/10.17261/Pressacademia.2017.430

Copyright: Published by PressAcademia and limited licenced re-use rights only.

\begin{abstract}
Sports marketing literature indicates that there are important relationships between importance of winning, schadenfreude, team identification, attitudinal and behavioral loyalty. The purpose of this study is to investigate importance of winning, schadenfreude on team identification and attitudinal and behavioral loyalty in the context of soccer. A structural model based on relationships is proposed in this study to explore the influence of importance of winning, schadenfreude on team identification and fans' loyalty. Convenience sampling was chosen in this study and empirical data were collected among soccer fans via an online and self-administration questionnaire. The data were analyzed using confirmatory factor analysis (CFA) and structural equation model with Amos 20.0 software. Findings indicate that there were a significant and strong relationship between team identification and attitudinal and behavioral loyalty. Furthermore, this paper shows that team identification was a mediator between importance of winning and schadenfreude, and loyalty. The results of this research have significant implications for the practice of sports marketing. Having said that, the study has significant implications as to how soccer teams' managers should be interpreting these variables or phenomenon.
\end{abstract}

Keywords: Attitudınal loyalty, behavioral loyalty, importance of winning, schadenfreude, team identification JEL Codes: M31, Z20

\section{KAZANMANIN ÖNEMI, NEFRET, TAKIM KIMLIĞi VE SADAKATI: TÜRKIYE'DEKI ANKET VERILERi iLE ILIŞKILERIN KEŞFEDILMESI}

\section{ÖZET}

Spor pazarlaması literatüründe kazanmanın önemi, nefret, takım kimliği, tutumsal ve davranışsal sadakat arasında önemli ilişkiler olduğu ortaya konulmuştur. Bu araştırmanın amacı kazanmanın önemi ve nefretin takım kimliği, davranışsal ve tutumsal sadakat üzerindeki etkilerinin futbol bağlamında incelenmesidir. Kazanmanın önemi ve nefretin takım kimliği, taraftar sadakati üzerindeki etkilerini araştıran ilişkisel model araştırma kapsamında önerilmiştir. Araştırmanın örneklemi kolayda örnekleme yöntemi ile oluşturulmuş, araştırma verileri online ve kişisel görüşme yoluyla toplanmışıı. Araştırma kapsamında doğrulayııı faktör analizi ve yapısal eşitlik modeli AMOS 22 programı kullanılarak analiz edilmiştir. Araştırmadan elde edilen bulgular takım kimliği, tutumsal ve davranışsal sadakat arasında güçlü ve anlamı ilişki olduğunu ortaya koymuştur. Bunun yanında, takım kimliğinin kazanmanın önemi, nefret ve taraftar sadakati arasındaki ilişkiye aracı etkisi olduğu ortaya konulmuştur. Bu araştırmadan elde sonuçlar spor pazarlaması uygulamaları için önemli öneriler içermektedir. Bunun yanında, futbol takım yöneticilerinin araştırma değişkenlerini nasıl yorumlaması gerektiğini ilişkin önemli öneriler araştırma kapsamında ortaya konulmuştur.

Keywords: Davranısssal sadakat, kazanmanın önemi, nefret, rakip takıma yönelik tutum, tutumsal sadakat. JEL Codes: M31, Z2O 


\section{GíRiş}

Günümüzde işletmelerin en önemli stratejik hedefleri arasında marka sadakati yaratmak gelmektedir. Sadakat, müşterilerin ürün veya hizmetten algıladıkları tatmini ifade etmenin yollarından biri olarak tanımlanmaktadır (Bloemer \& Kasper 1995). Marka sadakatinin işletmelerin satışlarına ve işletme maliyetlerine doğrudan etki eden birçok faydası olduğu yapılan çalışmalarca ortaya konulmuştur (Ballester \& Aleman 2001; Bloemer \& Kasper 1995; Dick \& Basu 1994). Bu sebepten dolayı marka ve müşteri arasında sağlanacak bağ|ılık, işletmeler için başarının anahtarı olarak görülmektedir (Ballester \& Aleman 2001).

Farklı sektörde ele alındığı üzere, müşteri sadakati kavramı spor sektöründe de birçok kez ele alınmıştır. Takım sadakati genel anlamda, seyircinin ilgi duyduğu takıma karşı zaman içerisinde gelişen sadakat ve bağıııı olarak tanımlanmaktadır. Geleneksel müşteri sadakatinin işletmelerin sürekliliği üzerindeki etkisi gibi, taraftar sadakati de spor kulüplerinin sürekliliği için hayati öneme sahiptir. Bu bağlamda, taraftar sadakatinin kulüpler için önemi, diğer sektörlerde işletmelerin müşterileri için arz ettiği öneme eşdeğerdir. Spor pazarlamacılarının üzerinde durması gereken en önemli konunun sadık taraftar kitlesi yaratmak olduğunu ifade etmişlerdir (Yoshida, Heere \& Gordon, 2015). Bu bağlamda spor sektöründe taraftarlar birer müşteri, futbol kulüplerinin ise birer marka olarak görülmeli ve diğer sektörlerde olduğu gibi taraftarlarında tıpkı müşteriler gibi ilgi ve intiyaçları belirlenmelidir (Tapp, 2004). Yoshida, Heere \& Gordon (2015), spor sektöründe sadık müşteri yaratmanın arkasında yatan nedenleri ortaya koyabilmenin hayati öneme sahip olduğunu ifade etmiştir. Spor yönetimi alanında yapılan çalışmalarda, spor taraftarlarının sadakatinin sadece sporla ilgili tek bir nesneyle ilişkili olmadığını ve basit bir şekilde ifade edilmesi mümkün olmayan çok daha karmaşık bir yapıda olduğu bu konuda yapılan bir çok çalışmada ortaya konulmuştur (Heere \& James, 2007; Katz \& Heere, 2013; Kwon, Trail \& Anderson, 2005; Mahony, Madrigal \& Howard, 2000; Trail, Anderson \& Fink, 2005; Tapp, 2004). Yapılan literatür taramasında spor taraftarlarının davranışsal sadakatlerini taraftarlar için kazanmanın önemi, rakip takıma yönelik nefret, takım kimliği ve tutumsal sadakat bağlamında inceleyen herhangi bir çalışmaya rastlanmamıştır. Bu bilgiler doğrultusunda bu araştırmanın amacı futbol taraftarlarının davranışsal sadakatlerini etkileyen yapılara ilişkin bir model önerisinde bulunarak yapılara arasındaki ilişkileri ortaya koymaktır.

\section{LITERATURE INCELEMESI}

\subsection{Takım Kimliği}

Sosyal kimlik teorisi takım kimliğinin temel dayanak noktası olarak kabul edilmektedir. Bu nedenle, takım kimliği üzerine yapılan çalışmalarda (Phua 2012; Murrell \& Dietz 1992) sosyal kimlik teorisinden yararlanılmıştır. Tajfel (1981) bireyin takım kimliği onun sosyal kimliğinin bir parçası olduğunu belirtmiş ve bu doğrultuda Phua (2012) takım kimliğinin sosyal kimliğin bir göstergesi olmasının yanı sıra sosyal bağlantıların kurulmasında ve korunmasında ilişkili olduğunu ifade etmişlerdir. Murrell \& Dietz (1992) sosyal kimlik teorisinden hareketle, taraftarların tutukları takımı kişisel benlik duygularının bir uzantısı olarak algıladıklarından dolayı bu takımlara karşı yüksek düzeyde bağııık hissettiklerini ifade etmiştir. Underwood Bond \& Baer (2001) kendi kimliğini bir takıma yakın hissedenlerin, kendilerini bu takımın bir parçası olarak hissedebildiklerini belirtmişlerdir.

Takım kimliği kavramıyla ilgili literatürde farklı tanımlar yapılmıştır. Örneğin Funk \& James (2001) takım kimliğini, bireyin takımı destekleyen diğer kişilerle ve takımla psikolojik bağlantı kurması olarak tanımlarken bu tanımla aynı doğrultuda, Wann \& Pierce (2003) takım kimliğini psikolojik ve davranışsal bir bağlılık olduğunu ifade etmiştir. Bunun yanında, Ashforth \& Mael (1999) takım kimliği kavramını daha somut olarak, seyircilerin takımlarının başarı ve başarısızıklarını kendi başarı ve başarısızıları olarak algılama düzeyleri olarak tanımlamışlardır. Buradan hareketle, "taraftarların takımlarıyla kurdukları psikolojik bağlantı" literatürde yer alan tanımların ortak noktasını oluşturduğu söylenebilir.

\subsection{Takım Sadakati}

Spor sektörünü diğer sektörlerden ayıran önemli özelliklerinden biri müşteri sadakatinin farklı olduğudur. Spor sektörü eğlence sektörleri içerisinde değerlendirilmesine rağmen diğer eğlence sektörlerinden farklı olarak spor sektöründe performasın ya da tatminin standartı ya da garantisi yoktur. Yani maçtan sonra taraftarlar takımlarının yenilmesiyle ya da kötü performans sergilemesiyle hayal kırıklığına uğrayabilmelerine rağmen sonraki maçlara gelmeye devam ederler (Yoshida, Heere, \& Gordon, 2015). Tapp, (2004) spor sektöründe taraftarların sadakatinin yalnız takımın güncel başarı durumundan etkilenebileceğini hatta futbol sektöründe bunun bile olanaksız olduğunu ifade etmiştir. Buna benzer olarak, Richardson \& O'Dwye (2003), yaptıkları çalışmadan elde ettikleri en güvenilir bilginin "futbol taraftarlarının takımlarına her durumda inatla sadık oldukları" olduğunu ifade etmişlerdir.

\subsection{Rakip Takıma Yönelik Nefret}

Kilduff, Elfenbein \& Staw (2010) rekabeti öznel ve doğal bir olgu olarak tanımlamışlar ve özellikle tarihsel çekişmeden etkilendiğini ifade etmişlerdir. Konu spor yönetim literatürü bağlamında incelendiği zaman, taraftarların rakiplerine yönelik genel anlamda olumsuz tutumları olduğu farklı araştırma yöntemlerince planlanmış çalışmalarda ortaya konulmuştur. 
Wenger \& Brown (2014) yaptıkları deneysel çalışmada spor taraftarlarının kendi takımlarına karşı içselleştirilmiş olumlu tutum içerisinde olduklarını fakat aynı çalışmada taraftarların rakip takımlara yönelik negatif tutumlar içinde oldukları ortaya koymuşlardır. Havard (2014) bu konuda yarı yapılandırılmış görüşme tekniğiyle nitel bir araştırma planlamış ve taraftarların rakip takımlara yönelik tutumlarının olumsuz olduğunu ifade etmiştir.

\subsection{Takım Kimliği ve Takım Sadakati ilişkisi}

Spor bilimleri literatüründe takım kimliği ve takım sadakati arasındaki ilişkiyi ortaya koyan birçok araştırma yapılmıştır. Kwon Trail \& James (2007) ve Bhattacharya \& Hayagreeva (1995) sürdürülebilir taraftar kitlesi(sadık taraftar) oluşturulmasında takım kimliği faktörünün pozitif yönde çok önemli etkileri olduğunu ortaya koymuşlardır. Lee \& Kang (2015) takım kimliği seviyesinin yükselmesi aynı zamanda kişlerin takımlarının aldığı olumsuz sonuçlardan etkilenme olasılığını azaltacağı ve bu durumun sadık taraftar göstergesi olduğu ifade etmişlerdir. Madrigal (2000) takım kimlik seviyesi düşük olan taraftarların, takımın sponsoru olan işletmelerin ürünlerini alma eğilimlerinin düşük olduğunu buna karşın, takım kimlik seviyesi yüksek olan taraftarların sponsor işletmelerin ürünlerini alma eğilimlerinin yüksek olduğunu ve bununda bir sadık taraftar göstergesi olduğunu ortaya koymuştur.

\subsection{Takım Kimliği ve Rakip Takım Yönelik Nefret ilişsisi}

Bireyler kendilerini bir grubun üyesi olarak tanımlama ihtiyacı içindedirler. Bu doğrultuda spor takım taraftarları kendilerini bir grup içerisinde hissetmeleri ve içinde bulunduğu grubu diğer gruplardan bazı kişisel değerlerle ayırt etmek intiyacındadırlar (Tajfel \& Turner, 1979; Hornsey \& Jetten, 2004). Kendilerini ait hissetikleri grupları karşılaştırmak için ise bir rakip gruba intiyaç duyarlar. Daha öncede belirtildiği gibi taraftarların rakip takımlarının yenilmesinden zevk almaktadırlar. Bu durumun sebebi onlara bu takımınların rakipleri olduğunun lanse edilmesinden kaynaklanmakta ve bu sebepten ötürü bir takıma rakip olmak taraftar kimlik düzeyini etkileyen önemli bir etken olduğu söylenebilir (Mahony \& Howard 1998). Bu doğrultuda taraftarlar kimliklerini tamamlamak için rakip takım belirlemek ihtiyacı içindedirler (Wenger \& Brown 2014).

\section{VERI VE YÖNTEM}

\section{1 Ölçme Araçları}

Araştırmada kullanılmak üzere futbol taraftarlarının davranışsal sadakat, tutumsal sadakat, takım kimliği, kazanmanın önemi ve rakip takıma yönelik nefret düzeylerini belirlemeye yönelik toplam beş yapıdan oluşan bir anket formu geliştirilmiştir. Anket formunda katılımcıların demografik özelliklerini belirlemeye yönelik dokuz soru yer almıştır. Oluştural bütün yapılar beşli likert ifade aralığında oluşturulmuştur (5-Kesinlikle Katılıyorum;1-Kesinlikle Katılmıyorum).

Katılımcıların takım kimlği seviyelerini ölçmek için Gwinner \& Swanson, (2003) tarafından geliştirilen 6 maddelik yapıdan kazanmanın önemini belirlemek için Dalakas \& Melancon, (2012) tarafından geliştirilen maddelerinden, takım sadakatini belirlemek için ise Tsiotsou (2013) tarafından geliştirilen yapının maddelerinden yararlanılmıştır. Araştırma kapsamında yararlanılan maddelerin hepsi araştırmanın amacı doğrultusunda revize edilmiştir.

\subsection{Veri Toplama ve Örneklem}

Araştırma kapsamında kolayda örnekleme yöntemiyle toplam 275 futbol taraftarına ulaşılmıştır. Anket formu online olarak google drive formu ve elden geri bildirim yoluyla futbol taraftarlarının görüşlerine sunulmuştur. Bu bilgiler doğrultusunda online olarak elden geri bildirim yoluyla toplam 201, elden geri bildirim yoluyla 74 futbol taraftarına ulaşılmıştır.

\section{BULGULAR VE TARTIŞMA}

\subsection{Doğrulayıcı Faktör Analizi}

Araştırma modeli Amos 20 programı aracılığıyla YEM uygulaması kapsamında ölçme modeli ve yapısal modelden oluşan iki aşamalı yaklaşımla test edilmiştir. Bu doğrultuda, Tutumsal Sadakat (4 madde), Davranışsal Sadakat (5 madde), Takım Kimliği (6 madde), Kazanmanın Önemi (3 madde), Rakip Takıma Yönelik Nefret (2 madde) oluşan ölçüm modeli doğrulayıcı faktör analizi ile test edilmiştir. Yapılan analiz neticesinde elde edilen uyum indeksleri ile ölçüm modelinin doğrulandığını ortaya konulmuştur $\left(X^{2}=343,190 p=0,000, X^{2 /} S D=2,186, G F I=0,880, C F I=0,961, T L I=0,953, I F I=0,961, R M S E A=0,068\right.$, $S R M R S=0,036$ ). Ölçüm modelinin uyuşum geçerliliğini belirlemek amaçlı bütün yapıların AVE (average variance extracted) değerleri hesaplanmış ve bütün değerlerin 0.50 'in üzerinde olduğu görülmüştür. Bunun yanında uyuşum geçerliliği için incelenen bütün faktör yüklerinin 0.70 üzerinde olduğu ortaya konulmuştur. Bu bilgiler doğrultusunda araştırmada kullanılan ölçüm modelinin geçerli ve güvenilir bir model olduğu ifade edilebilir.

\subsection{Araştırma Modeli}

Ölçme modelinin doğrulanmasının ardından, yapısal model test edilmiştir. Yapılan analizler sonucunda, modelde bazı modifikasyon önerileri olduğu görülmüş ve bu öneriler doğrultusunda yapılan iki modifikasyon neticesinde modelin kabul 
edilebilir uyum değerlerine ulaştığı görülmüştür $\left(X^{2}=388,376 p=0,000, X^{2} / S D=2,397, G F I=0,864, C F I=0,953, T L I=0,945, I F I\right.$ $=0,953$, RMSEA $=0,073$ ). Sonuç olarak yapısal modele ilişkin uyum iyiliği değerlerinin kabul edilebilir seviyede olduğu belirlenmiştir. Araştırmada modelinde var olan bütün yapıların çeşitli anlamlılık düzeyinde birbirleri ile ilişkili olduğu ortaya konulmuştur.

\section{SONUÇ}

Modern futbolun geçmişten günümüze geçirdiği dönüşüm ona endüstri niteliği kazandırmış ve bu endüstri içerisinde futbol taraftarları kulüpler için gelir yaratacak müşteri konumuna gelmiştir. Futbol endüstrisinin müşterisi konumunda bulunan taraftarların davranışsal sadakatlerini etkileyen yapıların ve bu yapılar arasındaki ilişkilerin ortaya konulması futbol kulüplerinin sürdürülebilirlikleri için oldukça önemlidir. Bu araştırma kapsamında elde edilen verilerin analizi sonucunda, futbol taraftarlarının takım kimliklerinin ve tutumsal sadakatlerinin davranışsal sadakatlerini ortaya koymada oldukça önemli olduğu yapılan analizler sonucunda bu alanda yapılmış diğer araştırmalara paralel olarak ortaya konulmuştur. Futbol taraftarlarının takım kimlik düzeylerinin rakip takıma yönelik nefret ve taraftarlar için kazanmanın öneminden etkilendiği ve bu doğrultuda bu yapının takım sadakatinin her iki boyutundada çeşitli düzeylerde etkili olduğu araştırma sonucunda elde edilmiştir.

\subsection{Yönetimsel Öneriler}

Bu araştırma sonuçlarının yönetimsel açıdan değerlendirilecek olursak, takım kimliğinin futbol taraftarlarının kulüplerine sadık davranışlar (maçlara katılma, lisansı ürün satın alma vb.) sergilemeleri için oldukça önemli olduğu ortaya konulmuştur. Sutton vd., (1997), takım kimlikleri yüksek olan taraftarların takımlarının performanslarından bağımsız olarak takımları için zaman ve para harcama töleranslarının yüksek olduğunu ortaya koymuştur. Bu araştırmadan elde edilen sonuçlarıda göz önüne alacak olursak futbol takımlarının ve sponsorlarının takım kimlik düzeyi yüksek taraftarlara yönelmeleri daha olumlu sonuçlar elde etmelerine olanak sağlayacaktır.

\section{KAYNAKLAR}

Ashforth, B. E., \& Mael, F. (1999). Organization, Social Identity Theory and the. Academy of Management Review, 14(1), 20-39.

Bhattacharya, C., \& Hayagreeva, R. (1995). Understanding the Bond of Identification: An Investigation of Its Correlates Among Art Museum Member. Journal of Marketing, 59(4), 46-57.

Ballester, E. D., \& Aleman, L. M. (2001). Brand Trust in the Context of Consumer Loyalty. European Journal of Marketing, 35(11/12), 1238 1258.

Bloemer, J. M., \& Kasper, H. D. (1995). The complex relationship between consumer satisfaction and brand loyalty. Journal of Economic Psychology, 16(2), 311-329.

Dalakas, V., \& Melancon, J. P. (2012). Fan identification, Schadenfreude toward hated rivals, and the mediating effects of Importance of Winning Index (IWIN). Journal of Services Marketing, 26(1), 51-59.

Dick, A. S., \& Basu, K. (1994). Customer Loyalty: Toward an Integrated Conceptual Framework. Journal of the Academy of Marketing Science, $100-110$.

Funk, D. C., \& James, J. (2001). The Psychological Continuum Model: A Conceptual Framework for Understanding an Individual's Psychological Connection to Sport. Sport Management Review, 4(2), 119-150.

Heere, B., \& James, J. D. (2007). Stepping Outside the Lines: Developing a Multi-dimensional Team Identity Scale Based on Social Identity Theory. Sport Management Review, 10(1), 65-91.

Hornsey, M. J., \& Jetten, J. (2004). The Individual Within the Group: Balancing the Need to Belong With the Need to Be Different. Personality and Social Psychology Review, 8(3), 248-264.

Lee, J. S., \& Kang, J.-H. (2015). Effects of Sport Event Satisfaction on Team Identification and Revisit Intent. Sport Marketing Quarterly, 24(4), 225-234.

Katz, M., \& Heere, B. (2013). Leaders and Followers: An Exploration of the Notion of Scale-Free Networks Within a New Brand Community. Journal of Sport Management, 27(4), 271-287.

Kilduff, G. J., Elfenbein, H. A., \& Staw, B. M. (2010). The Psychology of Rivalry: A Relationally Dependent Analysis of Competition. Academy of Management Journal, 53(5), 943-969.

Kwon, H. H., Trail, G. T., \& Anderson, D. S. (2005). Are Multiple Points of Attachment Necessary to Predict Cognitive, Affective, Conative, or Behavioral Loyalty? Sport Management Review, 8(3), 255-270. 
Madrigal, R. (2000). The Influence of Social Alliances with Sports Teams on Intentions to Purchase Corporate Sponsors' Products. Journal of Advertising, 29(4), 14-24.

Mahony, D. F., \& Howard, D. A. (1998). The impact of attitudes on the behavioral intentions of sport spectators. International Sports Journal, 2(2), 96-110.

Mahony, D. F., Madrigal, R., \& Howard, D. (2000). Using the Psychological Commitment to Team (PCT) Scale to Segment Sport Consumers Based on Loyalty. Sport Marketing Quarterly, 9(1), 15-25.

Murrell, A. J., \& Dietz, B. (1992). Fan Support of Sport Teams:The Effect of a Common Group Identity. Journal of Sports \& Exercise Psychology, 14(1), 28-39.

Phua, J. (2012). Use of Social Networking Sites by Sports Fans. Journal of Sports Media, 7(1), 109-132.

Richardson, B., \& O'Dwye, E. (2003). Football Supporters and Football Team Brands: a Study in Consumer Brand Loyalty. Irish Marketing Review, 16(1), 43-53.

Sutton, W. A., McDonald, M. A., Mime, G. R., \& Cimperman, J. (1997). Creating and Fostering Fan Identification in Professional Sports. Sport Marketing Quarterly, 6(1), 8-15.

Tajfel, H. (1981). Human groups and social categories. CUP Archive.

Tajfel, H., \& Turner, J. C. (1979). An integrative theory of intergroup conflict. The social psychology of intergroup relations, 33(47), 74.

Tapp, A. (2004). The loyalty of football fans - We'll support you evermore? Database Marketing \& Customer Strategy Management, 11(3), 203-215.

Tsiotsou, R. H. (2013). Sport Team Loyalty: Integrating Relationship Marketing and a Hierarchy of Effects. Journal of Services Marketing, $27(6), 458-471$.

Trail, G. T., Anderson, D. F., \& Fink, J. S. (2005). Consumer Satisfaction and Identity Theory: A Model of Sport Spectator Conative Loyalty. Sport MarHetIng Quarterly, 14(2), 98-111.

Underwood, R., Bond, E., \& Baer, R. (2001). Building Service Brands Via Social İdentity: Lesso From The Sports Marketplace. Journal of Marketing Theory \& Practice, 9(1), 1-13.

Wann, D. L., \& Pierce, S. (2003). Measuring Sport Team Identification and Commitment: An Empirical Comparison of the Sport Spectator Identification Scale and the Psychological Commitment to Team Scale. North American Journal of Psychology, 5(3), $365-372$.

Wenger, J. L., \& Brown, R. O. (2014). Investigating the Impact of Conference Realignment on Rivalry in Intercollegiate Athletics. Sport Marketing Quarterly, 114(2), 224-234.

Yoshida, M., Heere, B., \& Gordon, B. (2015). Predicting Behavioral Loyalty Through Community: Why Other Fans Are More Important Than Our Own Intentions, Our Satisfaction, and the Team Itself. Journal of Sport Management, 29, 318-333. 